\title{
COVID-19 Related Fears Among Mzuzu University's Nursing Students During Clinical Practice
}

\author{
Ferestas Mpasa \\ Masumbuko Baluwa \\ Florence Lungu \\ Mep Coretta Chipeta (ID \\ Getrude Munthali \\ Lucky Mhango \\ Ettah Chimbe \\ Alice Konyani \\ Department of Nursing and Midwifery, \\ Mzuzu University, Mzuzu, 2, Malawi
}

Correspondence: Ferestas Mpasa Mzuzu University, Department of Nursing and Midwifery, Private Bag 20I, Luwinga, Mzuzu, 2, Malawi

Tel +265888317160

Fax +265 I 320568

Email mpasa.f@mzuni.ac.mw
Purpose: Clinical practice during pandemics is known to bring additional fears to nursing students. The purpose of this study was to explore fears of Mzuzu University's nursing students nurses regarding resumption of clinical practice amidst the Coronavirus disease (COVID-19) pandemic.

Methods: The study used a qualitative approach employing a descriptive phenomenological design. Mzuzu University Research Ethics Committee (MZUNIREC) approved the study and issued MZUNIREC/DOR/20/06 as approval number. An independent person collected data through four focus group discussions with a purposefully selected sample of 40 consented nursing students who had completed clinical practice during the first wave of the COVID-19 pandemic. Data analysis was done manually using content analysis. The analysis started with transcription of the interviews. Following this, data were coded and categorized into themes and subthemes were established from participants' significant statements.

Results: Four major themes about the fears amongst the student nurses emerged. These were as follows: equipment and supplies; increased perceived risk for acquiring and transmitting COVID-19; stigma and discrimination and perceived fear of not having adequate learning. Conclusion: Clinical practice during the COVID-19 pandemic brings fear among nursing students and requires that implementers of nursing and midwifery programs prioritize ascertaining student's skill, emotional wellbeing and provision of adequate resources before deploying them to clinical areas.

Keywords: fears, student nurses, clinical experience, Corona virus disease, COVID-19

\section{Introduction}

In December 2019, an infection caused by a novel corona virus (2019-nCoV) was first reported in Wuhan, Hubei Province, China. The infection was later named Coronavirus disease 2019 (COVID-19) by the World Health Organization (WHO). ${ }^{1}$ Corona viruses belong to a large family of viruses known to cause respiratory tract infections. ${ }^{2}$

On 11th March 2020, WHO declared the COVID-19 as a global pandemic. Since then, there had been up to 697,244 confirmed cases, 33,257 deaths due to the disease in more than 204 countries as of the end of March 2021. ${ }^{3}$ The COVID-19 pandemic resulted in a global crisis, large-scale loss of life and human suffering. As a result of this, countries had implemented lockdown measures to reduce transmission of the virus. ${ }^{4}$ For instance, education institutions were closed. Different restrictions were imposed on social gatherings.

On 23rd March 2020, the government of Malawi closed all educational institutions to control the spread of the virus despite having no reported cases until 2 April 2020, when the first three cases were confirmed. These conditions were 
only relaxed 5 months later when the government lifted the lockdown. Following the relaxation of the conditions, Mzuzu University redeployed its nursing students to clinical areas on 14th September 2020 (MU/1/I1 8th September, 2020).

During the clinical allocation, all required personal protective equipment (PPE) such as disposable aprons, sanitizers, gloves, and surgical masks were provided. Furthermore, each nursing student was required to procure a scrub suit to be used in clinical practice. In addition to the PPE, the students were oriented through a one-hour presentation by one of the lecturers on COVID-19 preventive measures to be followed whilst in the clinical area.

Clinical learning is core to the training of nursing students and it facilitates the exposure to practical knowledge and acquisition of skills necessary for patients' care. ${ }^{5}$ Much as it is a requirement for nursing students to do clinical practice, the experience itself can be stressful and fearful to them. ${ }^{6}$ In addition to that, the presence of a disease outbreak can worsen the students' fears. Regarding the COVID-19 pandemic, the nursing students' risks of contracting and transmitting the virus during the clinical practicum were very high. ${ }^{6}$ This may increase their fears in clinical practicum activities.

Furthermore, in Borneo, among the university population COVID-19 pandemic caused fears and anxiety and other psychopathologies. ${ }^{7}$ The study was conducted to assess the after-effect of COVID-19 among 255 respondents of which $70 \%$ were students. Results showed that the respondents who were aged below 25 years had significantly higher levels of fear of COVID-19, depression, anxiety, and stress. In addition, the undergraduates faced a multitude of challenges from the point of view of mental health symptoms, such as current quarantine prospects, future employment uncertainties, the effect of delayed study completion and fear of lack of support from university authorities. These fears increased their level of psychopathologies. The authors concluded that psychological interventions and online tele-psychiatry should be strengthened and be used in managing the psychological distress. ${ }^{7}$

Furthermore, a cross-sectional study conducted in Malaysia involving 515 students, the aim was to establish the psychological process variables underlying psychopathology. Recognizing that the COVID-19 pandemic can affect students psychologically, the authors wanted to craft structured and sustainable psychological support programs with these students. Quarantined students had higher depressive symptoms, with female students scoring significantly higher for depression, anxiety, and stress. The authors concluded that timely psychological care for students may enable timely prevention and intervention programs for support during the pandemic. ${ }^{8}$

Also, in a cross-sectional study that was conducted in Mexico among nursing students and recent graduates, the results revealed the existence of a relationship of the age variable with fear, danger of contamination, traumatic stress, knowledge and minor socioeconomic consequences. Also, the presence of stress and knowledge illuminated the occurrence of fear regarding COVID-19 in half of the nursing students. ${ }^{9}$

In Malawi, research evidence shows that nursing students have been facing challenges in the clinical area even before the emergence of COVID-19 pandemic. ${ }^{10}$ In a study conducted locally among nursing students at a university, the results confirmed that the clinical learning experience in Malawi is indeed challenging. Apart from nursing students being used as a workforce because of shortage of qualified nursing staff, there is also gross lack of equipment and supplies. As a result, nursing students mostly utilized improvised equipment to perform nursing procedures, which compromises the quality of their clinical learning. ${ }^{10}$ In addition, the results also showed that nursing lecturers did not effectively support students during clinical placements and some nurses were not willing to teach.

Globally, countries responded differently to the emergence of the COVID-19 pandemic based on what was happening in their countries. In Malawi, the pandemic was declared a national disaster on 20th March 2020 by the former head of state. Thereafter, Mzuzu University officially closed operations on 23rd March 2020 to prevent the spread of the virus. Therefore, all students on campus and those that were in the clinical area were sent to their homes. Normally, nursing students are placed in the clinical areas for a period equivalent to the number of hours prescribed by the Nurses and Midwives Council of Malawi depending on the level of study. Besides, at Mzuzu University before going to clinical area nursing students are thoroughly oriented by their lecturers to the clinical objectives, which they are to achieve for specific clinical placement. However, during the occurrence of the first wave of the COVID-19 pandemic orientation of students to clinical objectives for the new disease (COVID19) was conducted after the nursing students had already reported to the clinical settings. After the ban was lifted, nursing students were informed to report back to the clinical setting where they were before the ban without going back to the campus. All the students reported to the specific clinical settings as instructed. Nevertheless, it was not well 
known by then what fears these nursing students would have, regarding resuming clinical practice amidst the COVID-19 pandemic. Therefore, this study aimed at exploring the fears of Mzuzu University nursing students regarding the resumption of clinical practice in the midst of the COVID-19 pandemic. This paper reports on the specific issues that caused fears among these nursing students as they worked in various clinical settings during the first wave of the COVID-19 pandemic.

\section{Materials and Methods Study Approach}

The study used a qualitative approach in order to obtain rich data from the nursing students who participated in the study. A qualitative approach is used when the focus of the researcher is on whether the quality of the data is obtained rather than the numbers. ${ }^{11}$

\section{Study Design}

The study employed a descriptive phenomenological design to explore the clinical experiences with a focus on fears that Mzuzu University student nurses/midwives had during the COVID-19 pandemic. The design was chosen because it describes the world as experienced by individuals in a particular phenomenon that is at the core of that experience. ${ }^{11}$ Clinical learning is a human experience and this justifies the need for a phenomenological inquiry. It is believed that only those who live the experience can best describe it. ${ }^{11}$ As such, the researchers wanted to get a full meaning and understanding of the fears that the Mzuzu
University nursing students had during their clinical experience during the first wave of the COVID-19 pandemic.

\section{Study Setting and Sample}

The study was conducted at Mzuzu University campus in December 2020 because by the time the study was approved, the nursing students had already completed their first clinical rotation that was done during the first wave of the COVID-19 pandemic September and December 2020. The researchers used purposeful sampling technique to achieve a required sample that gave rich data upon reaching data saturation. The technique enabled the researchers to get rich data regarding clinical experience from the voluntarily consented nursing students. Therefore, a total of 40 nursing students drawn from generic and upgrading groups composed the study sample. Four focus groups were formed with 10 participants in each. The groups comprised nursing students from different levels, clinical wards, units or departments, Table 1.

\section{Data Collection Tool}

The study used a self-developed focus group interview guide to collect data. The guide enabled the researchers to maintain consistency between interviews and bring to mind the main areas to be explored, thus increasing the credibility of the findings. ${ }^{12}$ The interview guide contained open-ended questions. The main question was "what were your fears regarding resumption of clinical practice in the midst of the COVID-19 pandemic"? The probe questions focused on thoughts, and perceptions regarding the fears

Table I Socio Demographic Characteristics of the Respondents Based on Wards/Departments Where They Worked During the First Wave of COVID-I9 Pandemic

\begin{tabular}{|l|l|l|l|l|l|}
\hline $\begin{array}{l}\text { FGD } \\
\text { NO }\end{array}$ & Program & $\begin{array}{l}\text { Level of } \\
\text { Study }\end{array}$ & Males & Females & Clinical Placement Areas \\
\hline I & $\begin{array}{l}\text { Bsc Nursing and Midwifery (upgrading cohort I 2018 } \\
\text { intake) }\end{array}$ & 2 & 5 & 5 & $\begin{array}{l}\text { STI, ART clinics and medical and } \\
\text { surgical wards }\end{array}$ \\
\hline 2 & $\begin{array}{l}\text { Bsc Nursing and Midwifery (upgrading cohort 2 2018 } \\
\text { intake) }\end{array}$ & I & 4 & 8 & Medical and surgical nursing wards \\
\hline 3 & $\begin{array}{l}\text { Bsc Nursing and Midwifery (upgrading cohort 3 2019 } \\
\text { intake }\end{array}$ & 1 & 4 & 4 & Family planning clinics \\
\hline 4 & $\begin{array}{l}\text { Bachelor of science nursing and midwifery 2018 } \\
\text { intake generic }\end{array}$ & 2 & 5 & 5 & ART, STI clinics, medical and surgical \\
wards,
\end{tabular}


which the nursing students had as they worked, in the clinical area.

\section{Data Collection}

Data were collected using four focus group discussions. In order to avoid bias, an independent person who is also a qualitative research expert and does not work at Mzuzu University collected the data. One of the rooms at the University was used to as a place for data collection. The room is at place which aides in non-interference by noise or human traffic during data collection. Field notes were used to clarify and verify matters that arose during the process of data collection as the nursing students utterly discussed and shared their experiences they had in the clinical area.

\section{Ensuring Methodological Rigor}

Rigor within qualitative research involves engaging in efforts that increase the confidence that research findings represent the meanings presented by participants. ${ }^{16}$ Rigor enhances the trustworthiness of the findings to ensure that they reflect the true meanings of participants' constructions of the phenomena under investigation. ${ }^{12-14}$ Methodological rigor was achieved through the steps that follow.

First, in order to ensure credibility, a member checking was done whereby the researcher returned to the participants to validate the findings. Considering the relationship between the nursing students included in the study and the researchers, the independent data collector also verified the findings. Secondly, dependability was achieved by maintaining consistency in the process of data collection specifically by using the same main questions in the interview guide Appendix 1, in all focus group discussions. Thirdly, conformability was achieved by including excerpts from the participants' narratives. This aimed at enhancing the credibility of findings and that the study findings are representative of the participants' views. Finally, the researchers provided a dense description of the research methodology and the research context so as to enable someone interested in making a transfer of data findings to reach a conclusion about whether transfer is possible or not.

\section{Data Analysis}

Data were analyzed using content analysis. Content analysis is an approach to quantify qualitative information by systematically sorting and comparing items of information in order to summarize the information. ${ }^{12}$ Qualitative content analysis involves inductive and deductive ways of processing data using three main phases: preparation, organization, and reporting of results. ${ }^{13}$ The study utilized the inductive approach, which consists of collecting suitable data for content analysis, making sense of the data, and selecting the unit of analysis.

First, all the researchers listened to the focus group discussions together for several times. Secondly, data was transcribed verbatim the interviews that were conducted in all the four focus group discussions in order to get familiarized with the data. The research team verified the transcription by re-reading the transcribed data while listening to the recorded data again in order to obtain a general sense about the whole context.

Thirdly, the organization phase included open coding, creating categories, and abstraction. ${ }^{13}$ This was done by identifying significant statements that pertained to the phenomena under study. Meanings from these significant statements were formulated and then sorted into categories, themes and subthemes. Fourthly, in the reporting phase, the findings were integrated into an exhaustive description of the Covid-related fears by the students during clinical practice. Finally, the researchers performed validation of findings by returning to the participants and data collector to compare the researchers' descriptive results with the nursing students experiences and data collected, respectively.

\section{Ethical Considerations}

Permission to conduct the study was granted by Mzuzu University Research Ethics Committee (approval number MZUNIREC/DOR/20/06). All the participants were assured that their participation in the study was voluntary and written informed consent was obtained prior to the interviews and discussions. Further to that consent was sought on the possibility of publication of their responses anonymously, to which all of them were in agreement. Voluntary participation and informed consent ensured that the study complied with ethical requirements complying with the Declaration of Helsinki. Additionally, the researchers ensured the research participants that they could withdraw at any time without facing reprimands. Confidentiality and anonymity of the participants were observed by conducting interviews in a private place and using codes for identification of the participants. The participants were informed that the 
information they provided would be used to improve services.

\section{Results}

\section{Demographic Data}

A total of 40 nursing students were recruited in the study of which eighteen (18) were males and twenty two (22) were females. Their level of study and area of clinical experience have been well detailed in Table 1 .

\section{Emerged Themes}

Four themes emerged from data analysis and these were: Equipment and supplies; Increased perceived risk for acquiring and transmitting the COVID-19; Stigma and discrimination; and Perceived fear of not learning. Each main theme had subthemes.

\section{Theme I: Equipment and Supplies}

Under this theme two (2) subthemes emerged and these were: personal protective equipment and medical equipment.

\section{Personal Protective Equipment}

When participants were asked about fears related to the clinical environment they were allocated to, they narrated that shortage of equipment and supplies in the clinical area brought a lot of fear on them. One participant narrated:

Much of the fear was to do with the lack of PPE in that we were bringing our own masks, our own gloves to protect us from the virus. (Participant 35)

We were given 10 marks for two weeks which means one mask per day. (Participant 7)

Another one had this to say:

Personal protective wear was not enough we were putting on one mask from morning to evening and the same mask again on the next day. I feared I would catch the virus. (Participant 34)

While yet another participant narrated:

We were supposed to use one mask for the whole day which was not very protective. We had one mask sometimes we used one mask for two days. (Participant 34)

Apart from the fact that the PPEs were inadequate, others articulated that the PPEs provided were inappropriate and of low standard.

One participant narrated:
We were given the protective equipment's which were not $100 \%$ protective to us like the face masks they were not those recommended by WHO. (Participant 8 )

Also another one added:

Our PPEs were not enough. WHO says we should use N95 masks but we used mere surgical masks. (Participant 3)

One participant expressed that PPEs were not enough and feared that they may not be given some of their own supply out stocked as evidenced in the following narrative:

My fear was that some of the staff may not give us resources if ours got finished. (Participant 4)

\section{Medical Equipment}

Some participants narrated fear related to lack of medical equipment to be used on them in case they catch the COVID-19, they may not access the use of life-saving equipment. One participant had this to say:

Malawi does not have much of the ventilators which help the person who has Covid 19, to breath. I am not sure if can access an oxygen concentrator if I contracted the virus?. (Participant 35)

\section{Theme 2: Increased Perceived Risk for Acquiring and Transmitting the COVID- 19}

Under this theme four subthemes emerged and these were: Highly contagious disease; new disease with little known; fear of dying early and ascertaining Covid status.

\section{Highly Contagious Disease}

The participants feared contracting and transmitting the virus to others because COVID-19 was a highly contagious disease. One participant narrated:

I realized that if I go to the clinical area and get the virus what about my siblings those whom am living close to. (Participant 6)

Also, participants feared that if they catch COVID-19, they will be put in quarantine and their learning may be put on hold. One of them had this to say:

My fear was that if I catch the disease I will be in quarantine for 14 days, there is a college regulation that if you miss clinical hours for some days you repeat a year. So that was my fear. (Participant 12) 


\section{New Disease Still Being Researched on}

The fact that COVID-19 was a disease that had just emerged and that research was still being conducted on it brought more fears on the participants since not much was known about it. One of them narrated:

We know the pathophysiology but this is a new disease research is still being done. There is not much information. The virus was new to everyone we didn't have much of background knowledge on the same. So that was my fear. (Participant 35)

Some participants expressed that the orientation given regarding the disease was not adequate; hence, they had fears because they did not know how to protect themselves as they provided care to the patients in the wards. Two of them narrated:

The virus was new to everyone we didn't have much of background knowledge on the same. (Participant 35)

... did not get enough orientation on the COVID 19 disease. Did not know the measures to use in patient care. (Participant 10)

\section{Fear of Dying Early}

The narratives also indicated that participants had fears that if they get infected with COVID-19 they may die early and may not accomplish their goals in life. One participant had this to say:

We were just told to go to clinical area on such a date. We knew little, I was afraid to die early, I will not accomplish my goals. (Participant 21)

While yet another narrated:

Mzuzu University did not orient me. We were afraid because people were dying. We could die too. (Participant 33)

Others were concerned with the state of one's own health fear of dying of COVID-19. One of them had this to say:

I was afraid due to my status. It is said that people with underlying conditions die more. So with my status I was afraid. (Participant 11)

\section{Ascertaining COVID-19 Status}

The fact that the COVID-19 status of the patients in the wards and that of those providing care were not ascertained brought fear on the participants. One of the participants narrated:

...... My fear was that I was working with patients who were not tested, their COVID-19 status was not known. (Participant 10)

Another one said:

I was afraid to touch my patients because their covid status was not known. (Participant 35)

\section{Theme 3: Stigma and Discrimination}

One sub theme emerged under this main theme and that is being isolated from and rejected by the community.

The narrations indicated that participants feared they would suffer discrimination by the community. One participant narrated:

My fear was stigma if I catch corona virus community members would neglect me not to associate with me. (Participant 31)

Another one had this to say:

Some other people in the house were afraid of me they thought I will bring the virus to them. (Participant 24)

Other participants feared rejection by transporters who ferry people to work places. One of them narrated:

Most of them also had fears to take health care workers because they were afraid that we may contract the disease. So my fears were so how am I going to travel to the workplace?. (Participant 31)

\section{Theme 4: Perceived Fear of Not Having Adequate Learning}

There were three subthemes that emerged under this theme. These were: uncertainty to learning; few patients in hospitals; and inadequate supervision.

\section{Uncertainty to Learning}

The narrations indicated that participants had fears that they may not be able to learn adequately and achieve their required objectives if lecturers did not supervise them frequently in the clinical area. One participant had this to say:

My fear was that may be the lecturers will not come to teach us or they will reduce their times of coming to 
supervise us in the clinical area. So how will I learn? (Participant 5)

Other participants feared that they may not be assessed in the clinical area. One of them narrated:

Who will come to assess me? Because am not done yet with assessments; how will I achieve those things? (Participant 7)

\section{Few Patients in Hospitals}

The presence of fewer patients in the hospitals where the students were practicing brought fears of experiencing compromised learning. One of them narrated:

How will I achieve those things? The hospitals that we were working in, there were not admitting many patients due to corona, of which we need to have a lot of patients so that we gain the experience (Participant 8). Another one had this to say:

But the department could only have 5 patients, but us students were 10 . So we could not gain the experience in medical conditions. (Participant 6)

\section{Discussion}

The findings suggest that students had fears to resume clinical practice due to COVID-19 pandemic due to lack of equipment and supplies. The PPEs provided to the students were the surgical masks, hand sanitizers, disposable aprons and gloves. These PPE were inadequate in terms of the number of masks supplied per student. For example, 10 disposable surgical masks per 2 weeks, which made the students to over use the same mask for a long time. A lack of adequate PPE puts students at risk of contracting the virus. These findings are in agreement with those ${ }^{15}$ who noted that taking care of infected persons without proper protective wear pauses the risk of contracting the virus. This realization was a source of anxiety and stress to the students, which was in agreement with ${ }^{15}$ whose study indicated an association between lack of protective personal equipment and fear of infection. The equipment was inappropriate, as the masks utilized were surgical instead of the recommended N95 as WHO explains in its interim guidance. ${ }^{4}$

Students also had a fear of handling patients whom they were not sure of their COVID-19 statuses as they had a fear of catching the virus and transmitting it to others. Similarly, the results of a study by author ${ }^{17}$ indicated that standing very close to infected people is one of the factors that facilitates easy spread of the corona virus. Therefore, the students' fear was justified as they would be close to infected patients in the course of rendering services to the patients. The other fear was that if they catch the disease, the illness would disturb their studies as they would be required to be in quarantine for no less than 14 days while their colleagues would continue with the studying program. Similarly, in a cross-sectional study, it was reported that $68.1 \%$ of students were worried about being infected by the COVID-19 virus. ${ }^{7,8}$ In addition, other studies have shown that levels of fear, anxiety and depression related to COVI-19 are higher in persons who are students. ${ }^{8,9}$

In our study, students were not sure of who was going to support them while in the clinical area as they were not certain of faculty members and clinical staff being able to supervise and teach them. This was because the COVID19 pandemic had forced the hospital management to reduce staffing levels as some were allocated to COVID19 isolation centers, while faculty member visits were also uncertain. Concurring with these results are those of a cross-sectional study conducted on nine Belgian nursing schools, where they found that on the overall, $77.44 \%$ of students $(n=515)$ felt they could discuss their concerns with the nursing school's clinical placement supervisor (agree or totally agree), 5.26\% $(\mathrm{n}=35)$ felt unsupported by the supervisor, others were neutral $(17.29 \%, \mathrm{n}=115)$.

Another fear was related to stigma that the students were subjected to in their places of accommodation and when boarding public transports. The members of the public were afraid to interact with the students thinking that they would transmit the virus to them from the hospital they were practicing. This created fear among the students as they were unsure of the next action their neighbors could take against them as they were aware that these students were potentially high-risk carriers of the virus. In this study, participants narrated that some of the taxi drivers were refusing to ferry them to their various clinical practice areas for fear of contracting the corona virus. Similarly, another study in Japan indicated that, Health Care Workers (HCWs) had been targeted for discrimination and abuse in off-duty hours and were stigmatized as "germs" in public spaces. Many suffered social sanctions in the form of social exclusion and even bullying. Such developments dilute the enthusiasm in the HCWs that target serving and saving the clients in the midst of COVID-19 pandemic. Nursing students are likely to be more fearful than qualified healthcare workers. 
The study findings showed that participants feared that their learning may be compromised because of less support from clinical and college staff, and lean clientele in the hospitals. In the nursing profession, adequate number of patients in hospitals enable vast scope of experiences for nursing students to gain skills. In Malawi, the cause of fewer numbers of patients in hospitals during the first wave of COVID-19 was related to strict measures on admission procedures, which focused on emergencies only. Similar to our findings, in Alberta, a populationbased retrospective study also revealed a significant reduction in both daily medical and surgical hospital admissions following the period of COVID-19 (March 16-September $23,2020)$. Without an adequate number of patients in the hospitals nursing students may not be able to achieve their clinical learning objectives to gain the required skills.

In our study, participants feared that clinical supervision by both college and clinical staff would be less, which would negatively affect their learning. Similarly, in a cross-sectional study conducted in Belgium, students identified gaps in practice during the pandemic which included the need for more psychosocial support, establishing (regular) contact with their clinical placement supervisor, recognition of the difficult work situation, and the need for more space to unwind. Therefore, in times of pandemics, the role of supervisors in clinical areas becomes more important to reduce fears and enhance student learning.

\section{Conclusions and Recommendations}

This study explored fears among nursing students while doing clinical activities amidst COVID-19 pandemic. The study revealed the issues that caused fears in students, such as equipment and supplies; risk for catching and transmitting COVID-19; stigma and discrimination and perceived risk of inadequate learning.

In agreement with authors 5, 8 and 10 we encourage that when students are deployed into clinical areas material, physical and psychological supports are essential to enhance their learning. The authors of this paper conclude that the findings of the study have shown other insights that nurse training institutions should prioritize regarding issues that cause fears amongst students in the clinical area, especially during pandemics. However, further research is required to ascertain abstract constructs such as level of fear, and courage to go on in practice, which may relate to fears among students regarding practice during pandemics in a resourceconstraint country like Malawi.
The authors hereby recommend that nurse training institutions should adequately prepare students' skills wisely and psychologically before deploying them for practice. Further, faculty members and clinical staff need to frequently update students on available scientific evidence on care and support for Covid-19 patients. Frequent updates will assist in dismissing myths and reduce which fear among students.

The findings of this study are from one public university in Malawi, Africa. The University, apart from other programs, trains Registered Nurse Midwives for Bachelor of Science and Master's Degree in the department of nursing and midwifery. It should be noted that this article reports findings of the students from this institution only. Therefore, there is a need for larger scale studies, which may include students from other institutions locally and even in the Southern Africa Region so that findings may be of a wider scope and be evidence-based generalized.

\section{Acknowledgment}

The authors would like to acknowledge the contribution of Miss Eunice Nyirenda, a lecturer at St. John's Institute of Health Sciences, for conducting the four focus group discussions during data collection for the study.

\section{Disclosure}

This study did not receive any support or sponsorship from any institution. The authors report no conflicts of interest in this work.

\section{References}

1. Shereen MA, Khan S, Kazimi A, Bashir N, Bashir N, Siddique R. COVID-19 infection: origin, transmission, and characteristics of human corona viruses. J Adv Res. 2020;24:91-98. doi:10.1016/j. jare.2020.03.005

2. Government of Malawi; Ministry of Health. Guidance on Home-Based Management of Persons with Asymptomatic and Mild Covid-19; 2020. WHO; 2020. Available from: https://malawi.un.org/en/89317-guidancehome-based-management-persons-asymptomatic-and-mild-covid-19. Accessed November 29, 2021.

3. Munthali GNC, Xuelian W. Covid-19 outbreak on Malawi perspective. Electron J Gen Med. 2020;17(4):em210. doi:10.29333/ejgm/7871

4. World Health Organization. Coronavirus Disease (COVID-19) Weekly Epidemiological Update and Weekly Operational Update; September 14, 2020:1-2.

5. Jamshidi N, Molazem Z, Sharif F, Torabizadeh C, Kalyani MN. The challenges of nursing students in the clinical learning environment: a Qualitative Study. Sci World J. 2016;2016:1846178.

6. Ogolodom MP, Mbaba AN, Alazigha N, et al. Knowledge, attitudes and fears of healthcare workers towards the Corona Virus Disease (COVID-19) pandemic in South-South, Nigeria. Health Sci J Sp. 2020;1:002.

7. Kassim MA, Pang NT, Mohamed NH, et al. Relationship between fear of COVID-19, psychopathology and sociodemographic variables in Malaysian population. Int J Ment Health Addict. 2021;7:1-8. 
8. Pang NTP, Nold Imon GN, Johoniki E. Fear of COVID-19 and COVID-19 stress and association with sociodemographic and psychological process factors in cases under surveillance in a frontline worker population in Borneo. Int J Environ Res Public Health. 2021;18:7210. doi:10.3390/ijerph18137210

9. Fernandez IAM, Moreno SC, Diaz LC, Gallegos-Torres RM, Fernandes JAM, Martines EKH. Fear, stress, and knowledge regarding COVID-19 in nursing students and recent graduates in Mexico. Invest Educ Enferm. 2021;39(1):e05.

10. Mbakaya BC, Kalembo FW, Zgambo M, et al. Nursing and midwifery students' experiences and perception of their clinical learning environment in Malawi: a mixed-method study. BMC Nurs. 2020;19(1):1-14. doi:10.1186/s12912-020-00480-4

11. Creely. 'Understanding things from within'. A husserlian phenomenological approach to doing educational research and inquiring about learning. Int J Res Method Educ. 2016;41:1-19.

12. Boyce C, Neale P. Conducting In-Depth Interviews: A Guide for Designing and Conducting In-Depth Interviews for Evaluation Input, Monitoring and Evaluation - 2. Pathfinder International; 2006.

13. Elos S, Kyngas H. The qualitative content analysis process. $J A d v$ Nurs. 2008;62:107-115. doi:10.1111/j.1365-2648.2007.04569.x

14. Karnieli-Miller O, Strier R, Pessac L. Power relations in qualitative research. Qual Health Res. 2009;19(2):279-289. doi:10.1177/ 1049732308329306
15. Msiska G, Smith P, Fawcett T. The "lifeworld" of Malawian undergraduate student nurses: the challenge of learning in resource poor clinical settings. Int J Afr Nurs Sci. 2014;1:35-42. doi:10.1016/j. ijans.2014.06.003

16. Lietz C, Langer CL, Furman R. Establishing trustworthiness in qualitative research in social work: implications from a Study Regarding Spirituality. Qual Soc Work. 2006;5(4):441-458. doi:10.1177/ 1473325006070288

17. Aslan H, Pekince H. Students' views on the COVID-19 pandemic and their perceived stress levels. Perspect Psychiatr Care. 2021;57 (2):695-701.

18. Ulenaers D, Grosemans J, Schrooten W, Berg J. Clinical placement experiences of nursing students during COVID 19 pandemic: a cross sectional study. Nurse Educ Today. 2021;99:104746. doi:10.1016/j. nedt.2021.104746

19. Shimizu K, Leesa L. Defamation against healthcare workers during COVID pandemic. Letter to editor. Int J Health Policy Manag. 2020; $\mathrm{x}(\mathrm{x}): 1-2$.

20. Rennert-May E, Leal J, Thanh NX, et al. The impact of COVID-19 on hospital admissions and emergency department visits: a population-based study. PLoS One. 2021;16(6):e0252441. doi:10.1371/journal.pone.0252441
Nursing: Research and Reviews

\section{Publish your work in this journal}

Nursing: Research and Reviews is an international, peer-reviewed, open access journal publishing original research, reports, reviews and commentaries on all aspects of nursing and patient care. These include patient education and counseling, ethics, management and organizational issues, diagnostics and prescribing, health outcomes,

\section{Dovepress}

economics and resource management, improving patient safety in all settings. The manuscript management system is completely online and includes a very quick and fair peer-review system. Visit http://www. dovepress.com/testimonials.php to read real quotes from published authors. 